\title{
GOVERNAMENTALIDADE, BIOPOLÍTICA E VIDA PRECÁRIA: A PANDEMIA DE COVID-19 NO BRASIL
}

\author{
GOVERNMENTALITY, BIOPOLITICS AND PRECARIOUS LIFE: \\ THE COVID-19 PANDEMIC IN BRAZIL
}

\author{
GOVERNAMENTALIDAD, BIOPOLIITICA Y VIDA PRECARIA: \\ LA PANDEMIA DE COVID-19 EN BRASIL
}

\author{
Renato DuRo Dias \\ http://orcid.org/0000-0002-9849-1332 / http://lattes.cnpq.br/9894300167305005 / renatodurodias@gmail.com
}

Faculdade de Direito e Programa de Pós-graduação em Direito - FURG Rio Grande, RS, Brasil

\begin{abstract}
RESUMO
O presente artigo problematiza a pandemia do Coronavírus (COVID-19) no Brasil, tendo como referência as leituras teóricas de Michel Foucault, Judith Butler, Nikolas Rose e Byung-Chul Han. O estudo de abordagem qualitativa se insere no campo das investigações transdisciplinares de base teórico-crítica e se utiliza dos conceitos de vida precária, de biopolítica e de governamentalidade. Esta pesquisa está estruturada em três (03) etapas. Primeiramente, se apresentam os elementos contextuais da pandemia do Coronavírus (COVID-19). A seguir, procura-se entender como estes marcos teóricos contribuem contemporaneamente nas análises micro e macrossociais em diálogo com a emergência da doença. Ao fim, procura-se analisar a situação pandêmica no Brasil. Para tanto, como problema de pesquisa, indica-se: em que medida os conceitos de vida precária, de biopolítica e de governamentalidade podem desvelar o contexto da pandemia de COVID-19 no Brasil? Espera-se que os diálogos aqui apresentados possam ser um ponto de reflexão, a fim de compreender os desafios, os limites e as possibilidades da realidade brasileira frente à emergência da COVID-19.
\end{abstract}

Palavras-chave: Biopolítica; Brasil; COVID-19; Governamentalidade; Vida precária.

\begin{abstract}
This article discusses the Coronavirus pandemic (COVID-19) in Brazil, having as reference the theoretical readings of Michel Foucault, Judith Butler, Nikolas Rose and Byung-Chul Han. The qualitative approach study is inserted in the field of transdisciplinary investigations with a theoretical-critical basis and uses the concepts of precarious life, biopolitics and governmentality. This research is structured in three (03) stages. First, the contextual elements of the Coronavirus pandemic (COVID-19) are presented. Next, we seek to understand how these theoretical frameworks contribute at the same time to micro and macrosocial analyzes in dialogue with the emergence of the disease. In the end, we seek to analyze the pandemic situation in Brazil. Therefore, as a research problem, it is indicated: to what extent can the concepts of precarious life, biopolitics and governmentality unveil the context of the pandemic of COVID-19 in Brazil? It is hoped that the dialogues presented here can be a point of reflection, in order to understand the challenges, limits and possibilities of the Brazilian reality in the face of the emergence of COVID-19.
\end{abstract}

Keywords: Biopolitics; Brazil; COVID-19; Governmentality; Precarious life.

\section{RESUMEN}

Este artículo analiza la pandemia del coronavirus (COVID-19) en Brasil, teniendo como referencia las lecturas teóricas de Michel Foucault, Judith Butler, Nikolas Rose y Byung-Chul Han. El estudio de enfoque cualitativo se inserta en el campo de las investigaciones transdisciplinarias con una base teórico-crítica y utiliza los conceptos de vida precaria, biopolítica y gubernamentalidad. Esta investigación está estructurada en tres (03) etapas. Primero, se presentan los 
elementos contextuales de la pandemia del coronavirus (COVID-19). A continuación, buscamos comprender cómo estos marcos teóricos contribuyen al mismo tiempo a los análisis micro y macrosociales en diálogo con la aparición de la enfermedad. Al final, buscamos analizar la situación de la pandemia en Brasil. Por lo tanto, como problema de investigación, se indica: ¿en qué medida los conceptos de vida precaria, biopolítica y gubernamentalidad pueden desvelar el contexto de la pandemia de COVID-19 en Brasil? Se espera que los diálogos presentados aquí puedan ser un punto de reflexión, para comprender los desafíos, límites y posibilidades de la realidad brasileña ante el surgimiento de la COVID-19.

Palabras clave: Biopolítica; Brasil; COVID-19; Governamentalidad; Vida precaria.

\section{SUMÁRIO}

INTRODUÇÃO; 1 A PANDEMIA DO CORONAVÍRUS (COVID - 19); 2 GOVERNAMENTALIDADE, BIOPOLÍTICA E VIDA PRECÁRIA; 2.1 A GOVERNAMENTALIDADE E A BIOPOLÍTICA DE MICHEL FOUCAULT, A ALMA GOVERNADA DE NIKOLAS ROSE E A PSICOPOLÍTICA DE BYUNG-CHUL HAN; 2.2 VIDA PRECÁRIA EM BUTLER; 3. A COVID - 19 NO BRASIL: DIÁLOGOS NECESSÁRIOS PARA O AMANHÃ; CONCLUSÃO; REFERÊNCIAS.

\section{INTRODUÇÃO}

O presente artigo problematiza a emergência imposta pela pandemia do Coronavírus (que causa a doença da COVID-19) no Brasil, tendo como referência as leituras teóricas contemporâneas de Michel Foucault, Judith Butler, Nikolas Rose e Byung-Chul Han, utilizandose, especialmente, dos conceitos de vida precária, da biopolítica e da governamentalidade. 0 estudo de abordagem qualitativa se insere no campo das pesquisas transdisciplinares, que procuram compreender como uma pandemia mundial gera efeitos e reflexões em vários campos da ciência, tais como saúde, direito (sociais aplicadas) e humanidades.

Importa afirmar que essa investigação se enquadra ao que se poderia denominar de estudos de base teórico-crítica. Dessa forma, esse estudo se estrutura em três (03) etapas. Primeiramente, se apresentam os elementos contextuais da pandemia do Coronavírus (causador da (OVID-19). A seguir, explicitam-se as principais categorias teóricas, procurando entender como esses marcos contribuem contemporaneamente nas análises micro e macrossociais. Por último, reflexiona-se sobre essas categorias em diálogo com a crise e a emergência da doença, bem como a fraturação social vivida em nosso país.

A partir desse ferramental de variadas vertentes, pretende-se discutir como o contexto pandêmico emergencial vem afetando a população brasileira na constituição ou não de sujeitos cidadãos. Para tanto, como problema de pesquisa, indica-se: em que medida os conceitos de vida precária, de biopolítica e de governamentalidade podem desvelar o contexto da pandemia 
de COVID-19 no Brasil? Espera-se que os diálogos manejados ao longo desse texto, a partir de autores e autoras que tanto contribuem para pensar a contemporaneidade, possam ser um ponto de partida, a fim de compreender os desafios, os limites e as possibilidades da realidade brasileira em tempos de pandemia de COVID-19.

\section{A PANDEMIA DO CORONAVÍRUS (COVID-19)}

Desde o seu surgimento, na cidade chinesa de Wuhan, até sua propagação em vários países, o novo Coronavírus (causador da doença denominada COVID-19) tem deixado um rastro de mortes e de infecções numa escala jamais vista, quando se trata de se referir a pandemias em esfera global. Aproximadamente dezessete milhões e seiscentas e sessenta mil pessoas infectadas, seiscentos e oitenta mil mortes, em duzentos e dezesseis países (Quadro 1) ${ }^{1}$.

Quadro 1 - Casos confirmados, mortes e áreas afetadas pela COVID-19.

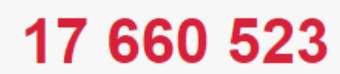

Confirmed cases

Last update: 1 August 2020, 21:00 GMT-3

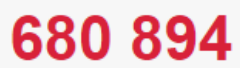

Confirmed deaths

Last update: 1 August $2020,21 \cdot 00$ GMT-3

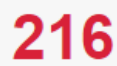

Countries, areas or territories with cases

Last update: 1 August 2020, 21:00 GMT-3

Fonte: Organização Mundial de Saúde, 2020.

O primeiro alerta foi recebido pela Organização Mundial da Saúde (OMS) em 31 de dezembro de 2019. As autoridades chinesas atentaram para o surgimento, na cidade de Wuhan (11 milhões de habitantes), de uma série de casos de pneumonia de origem desconhecida. A partir deste primeiro evento a OMS procurou seguir protocolos científicos, dando transparência e mantendo informada a população mundial, conforme se percebe na cronologia da Tabela 1.

1 WORLD HEALTH ORGANIZATION. Coronavirus disease (COVID-19) pandemic. Disponível em: https://www.who.int/emergencies/diseases/novel-coronavirus-2019 . Acesso em: 02 ago. 2020. 
Tabela 1 - Breve cronologia da COVID-19.

\begin{tabular}{|c|c|}
\hline DATA & OCORRÊNCIA \\
\hline 31 de dezembro de 2019 & $\begin{array}{l}\text { A China relata um conjunto de casos de pneumonia em Wuhan, } \\
\text { província de Hubei. Mais tarde, é determinado que eles são } \\
\text { causados por um novo coronavírus. }\end{array}$ \\
\hline 5 de janeiro de 2020 & $\begin{array}{l}\text { A OMS publica sua primeira parte sobre surtos epidêmicos do novo } \\
\text { vírus, uma publicação de referência técnica para a comunidade } \\
\text { global de saúde e pesquisa pública e a mídia. A parte contém uma } \\
\text { avaliação de risco e uma série de recomendações, além de } \\
\text { informações fornecidas pela China à Organização sobre a situação } \\
\text { dos pacientes e a resposta da saúde pública ao grupo de casos de } \\
\text { pneumonia de Wuhan. }\end{array}$ \\
\hline 10 de janeiro de 2020 & $\begin{array}{l}\text { A OMS publica online um conjunto abrangente de diretrizes } \\
\text { técnicas com recomendações para todos os países sobre como } \\
\text { detectar casos, realizar testes de laboratório e gerenciar casos em } \\
\text { potencial. As diretrizes são baseadas no conhecimento atual do } \\
\text { vírus. A orientação é encaminhada aos diretores regionais da OMS } \\
\text { para emergências para distribuição aos representantes dos países } \\
\text { da OMS. }\end{array}$ \\
\hline $16-24$ de fevereiro de 2020 & $\begin{array}{l}\text { A missão conjunta OMS-China, envolvendo especialistas da } \\
\text { Alemanha, Canadá, Estados Unidos (Centros de Controle e } \\
\text { Prevenção de Doenças, Institutos Nacionais de Saúde), Japão, } \\
\text { Nigéria, República da Coréia, Rússia e Cingapura, fica em Pequim } \\
\text { por um tempo e viaja para Wuhan e duas outras cidades. Seus } \\
\text { membros conversam com autoridades de saúde, cientistas e o } \\
\text { pessoal das unidades de saúde. Elabora-se um informe da missão } \\
\text { conjunta }{ }^{2} \text {. }\end{array}$ \\
\hline 3 de março de 2020 & $\begin{array}{l}\text { A OMS publica o Plano Estratégico de Preparação e Resposta para a } \\
\text { comunidade internacional para ajudar os Estados com sistemas de } \\
\text { saúde mais frágeis a se protegerem. }\end{array}$ \\
\hline 11 de março de 2020 & $\begin{array}{l}\text { Profundamente preocupada com os níveis alarmantes de } \\
\text { propagação da doença e sua gravidade, e níveis alarmantes de } \\
\text { inação, a OMS determina em sua avaliação que o COVID-19 pode } \\
\text { ser caracterizado como uma pandemia. }\end{array}$ \\
\hline 13 de março de 2020 & $\begin{array}{l}\text { O Fundo de Resposta à Solidariedade contra a COVID-19 é criado } \\
\text { para receber doações de indivíduos, empresas e instituições. }\end{array}$ \\
\hline
\end{tabular}

${ }^{2}$ WORLD HEALTH ORGANIZATION. Report of the WHO-China Joint Mission on Coronavirus Disease 2019 (COVID-19). Disponível em: https://www.who.int/docs/default-source/coronaviruse/who-china-jointmission-on-covid-19-final-report.pdf. Acesso em: 10 abr. 2020. 


\begin{tabular}{|c|c|}
\hline 18 de março de 2020 & $\begin{array}{l}\text { A OMS e seus parceiros lançam o estudo Solidarity, um estudo } \\
\text { clínico internacional que visa gerar dados robustos de todo o } \\
\text { mundo para encontrar os tratamentos mais eficazes para a COVID- } \\
\text { 19. }\end{array}$ \\
\hline 02 de abril de 2020 . & $\begin{array}{l}\text { A OMS apresenta evidências de transmissão de pessoas } \\
\text { sintomáticas, pré-sintomáticas e assintomáticas com COVID-19 e } \\
\text { observa que a transmissão pode ocorrer a partir de um caso pré- } \\
\text { sintomático, ou seja, antes do início dos sintomas. }\end{array}$ \\
\hline 20 de abril de 2020 & $\begin{array}{l}\text { A Assembleia Geral das Nações Unidas adota uma resolução } \\
\text { intitulada "Cooperação internacional para garantir o acesso global } \\
\text { a medicamentos, vacinas e equipamentos médicos com os quais } \\
\text { lidarão com a COVID-19". }\end{array}$ \\
\hline 18 e 19 de maio & $\begin{array}{l}\text { Na } 73^{a} \text { Assembleia Mundial da Saúde, a primeira a ser realizada } \\
\text { virtualmente, uma resolução histórica é aprovada para unir o } \\
\text { mundo na luta contra a pandemia do COVID-19, copatrocinado por } \\
\text { mais de } 130 \text { países - o maior número já registrado - e adotado por } \\
\text { consenso. } 14 \text { chefes de estado participam das sessões de abertura } \\
\text { e encerramento. }\end{array}$ \\
\hline 05 de junho & $\begin{array}{l}\text { A OMS atualiza as diretrizes sobre o uso de máscaras para controlar } \\
\text { o COVID-19, que fornece informações atualizadas sobre quem deve } \\
\text { usar uma máscara e quando usá-la, bem como os materiais dos } \\
\text { quais as máscaras devem ser feitas. }\end{array}$ \\
\hline 17 de junho & $\begin{array}{l}\text { A OMS anuncia a descontinuação do grupo de tratamento com } \\
\text { hidroxicloroquina do estudo Solidarity, que visa encontrar um } \\
\text { tratamento eficaz contra a COVID-19. }\end{array}$ \\
\hline 26 de junho & $\begin{array}{l}\text { O Acelerador de Acesso a Ferramentas contra a COVID-19 publica } \\
\text { os argumentos consolidados a favor do investimento e pede um } \\
\text { investimento de US } \$ 31,3 \text { bilhões nos próximos } 12 \text { meses em testes } \\
\text { de diagnóstico, tratamentos e vacinas. }\end{array}$ \\
\hline
\end{tabular}

Fonte: Elaborado pelo autor com base nos dados ${ }^{3}$ da OMS, 2020.

Trata-se, portanto, de uma pandemia em que a novidade é um Coronavírus.

Os coronavírus são uma extensa família de vírus que podem causar doenças em animais e humanos. Em humanos, sabe-se que vários coronavírus causam infecções respiratórias que podem variar do resfriado comum a doenças mais graves, como a síndrome respiratória do Oriente Médio (MERS) e a síndrome

3 ORGANIZACIÓN MUNDIAL DE LA SALUD. Cronología de la respuesta de la OMS a la COVID-19. 30 jun. 2020. Disponível em: https://www.who.int/es/news-room/detail/29-06-2020-covidtimeline. Acesso em: 02 ago. 2020. 
respiratória aguda grave (SARS). 0 coronavírus descoberto mais recentemente causa a doença de coronavírus (COVID-19) ${ }^{4}$.

Diariamente a Organização Mundial da Saúde atualiza os números de mortos e infectados pela COVID-19 por meio de relatórios ${ }^{5}$ e mapas, conforme a Figura 1. Esses dados são fundamentais para o acompanhamento do avanço da pandemia, bem como para monitorar as ações sanitárias desenvolvidas em várias partes do planeta.

Figura 1: Mapa com o número de casos confirmados.

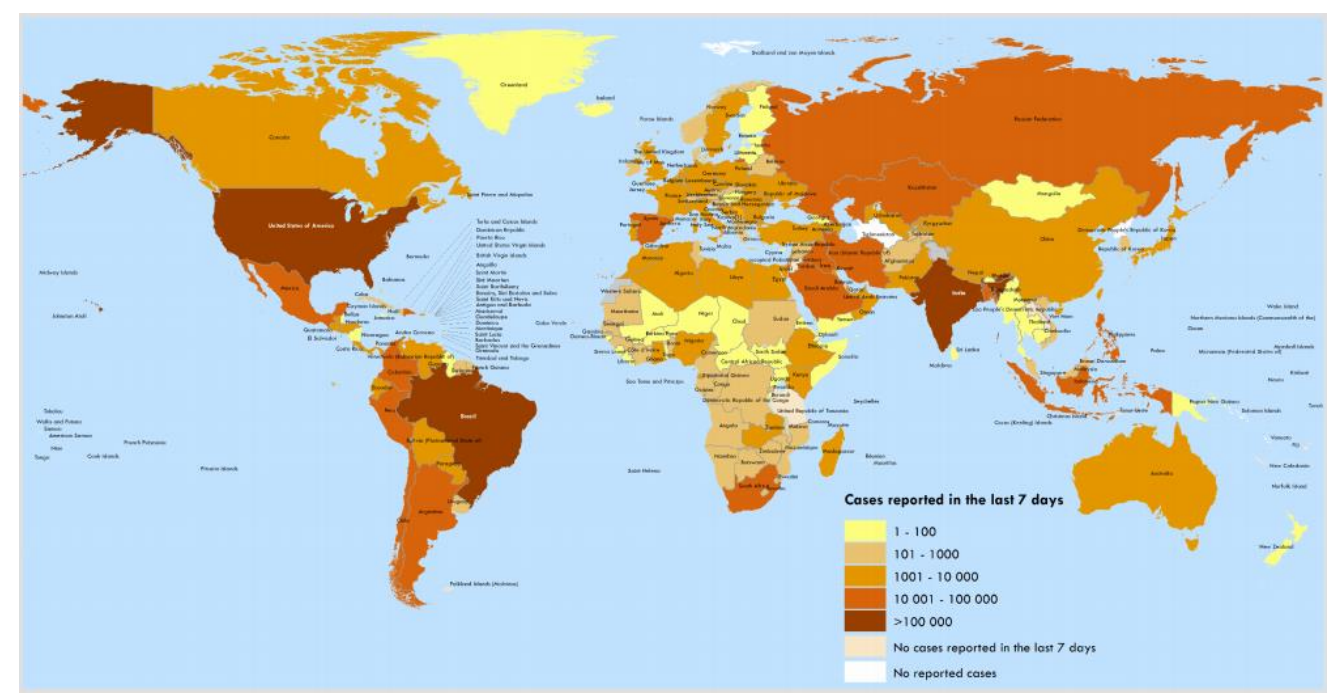

Fonte: OMS, $2020 .^{6}$

A Organização Mundial da Saúde (OMS) tem expressado sua preocupação com a ampliação da força de contágio do vírus nas cidades que são marcadas pelos seus altos índices de desigualdade social e, consequentemente, pelo precário acesso ao saneamento básico local. No Brasil, em que os índices de desigualdade são alarmantes, a COVID-19 pode precarizar ainda mais milhares de vidas que não possuem nenhuma espécie de proteção do Estado. No caso do

4 WORLD HEALTH ORGANIZATION. Coronavirus disease (COVID-19) pandemic. Disponível em: https://www.who.int/emergencies/diseases/novel-coronavirus-2019. Acesso em: 02 ago. 2020.

5 WORLD HEALTH ORGANIZATION. Coronavirus disease (COVID-19) pandemic. Disponível em: https://www.who.int/emergencies/diseases/novel-coronavirus-2019 . Acesso em: 02 ago. 2020.

${ }^{6}$ WORLD HEALTH ORGANIZATION. Coronavirus disease (COVID-19). Situation Report - 194. Disponível em: https: / /www.who.int/docs/default-source/coronaviruse/situation-reports/20200801-covid-19-sitrep194.pdf?sfvrsn=401287f3_2. Acesso em: 02 ago. 2020. 
Gini, indicador que o IBGE utiliza para medir a concentração de renda, teve o maior aumento em sua série histórica ${ }^{7}$.

Indicador de desigualdade permanece no nível mais alto da série 0 índice de Gini é um indicador que mede concentração e desigualdade econômica e varia de 0 (perfeita igualdade) até 1 (máxima concentração e desigualdade). Quando calculado para o rendimento médio mensal recebido de todos os trabalhos, ele se manteve em 0,509 em 2019. O índice tinha caído entre $2012(0,508)$ e $2015(0,494)$, mas subiu para 0,501 em 2016, mantendo-se o valor em 2017, e depois para 0,509 em 2018. ${ }^{8}$

Nesse sentido, corre-se o risco de ter um cenário explícito de ampliação das desigualdades sociais, regionais, econômicas, raciais e de gênero. A condição humana baseada em algumas características, como a raça, as identidades de gêneros e/ou sexual experimentadas pelos sujeitos, é fortemente arraigada no imaginário social e vem sustentando desigualdades, discriminações, abjeções e não reconhecimento de direitos ${ }^{9}$. Faz-se necessário, então, desvelar os mecanismos pelos quais essas precarizações e desigualdades podem se ampliar no contexto brasileiro. Para tal, utiliza-se da "pequena caixa de ferramentas" apresentada por Foucault, somando-se aos estudos de Butler, Han e Rose, entendendo que destas potentes escritas emergirão possíveis desdobramentos.

\section{GOVERNAMENTALIDADE, BIOPOLÍTICA E VIDA PRECÁRIA}

Reconhecido como o autor que discute o poder, Michael Foucault preocupa-se em entender, sobretudo, como as relações de poder afetam as pessoas. Segundo Foucault, “o poder não possui uma identidade própria, unitária e transcendente, mas está distribuído em toda a

\footnotetext{
7 INSTITUTO BRASILEIRO DE GEOGRAFIA E ESTATÍSTICA. PNAD Contínua 2019: rendimento do 1\% que ganha mais equivale a 33,7 vezes o da metade da população que ganha menos. Editoria: Estatísticas Sociais, 06 maio 2020. Disponível em: https://agenciadenoticias.ibge.gov.br/agencia-sala-de-imprensa/2013-agenciade-noticias/releases/27594-pnad-continua-2019-rendimento-do-1-que-ganha-mais-equivale-a-33-7-vezeso-da-metade-da-populacao-que-ganha-menos. Acesso em: 02 ago. 2020.

8 INSTITUTO BRASILEIRO DE GEOGRAFIA E ESTATÍSTICA. PNAD Contínua 2019: rendimento do 1\% que ganha mais equivale a 33,7 vezes o da metade da população que ganha menos. Editoria: Estatísticas Sociais, 06 maio 2020. Disponível em: https://agenciadenoticias.ibge.gov.br/agencia-sala-de-imprensa/2013-agenciade-noticias/releases/27594-pnad-continua-2019-rendimento-do-1-que-ganha-mais-equivale-a-33-7-vezeso-da-metade-da-populacao-que-ganha-menos. Acesso em: 02 ago. 2020.

${ }_{9}$ DIAS, Renato Duro; BRUM, Amanda Netto. (Re) significando o discurso dos direitos humanos: um diálogo a partir da educação em e para os direitos humanos. Revista Quaestio iuris. vol. 10, n. 04, Rio de Janeiro, 2017. 2396-2412. D. Disponível em:
} publicacoes.uerj.br/index.php/quaestioiuris/article/view/25690. Acesso: 02 ago. 2020. 
estrutura social e é sempre produzido, socialmente produzido." ${ }^{10}$ Dessa feita, equivoca-se quem, apressadamente, encontra em Foucault uma única concepção negativa de poder. Para ele, não é só a negatividade do poder exercido pelo Estado que transborda das relações, mas sim suas características produtivas (e, portanto, positivas).

É sobre a visão positiva de poder, a produção de desejos e de sentidos que Foucault está mais preocupado. A partir da disciplina (disciplinamento dos corpos), da vigilância (olhar) e do saber sobre, Foucault analisa como se organiza o espaço, se controla o tempo e se docilizam os corpos. Dessa forma, as tecnologias de poder tornam-se a preocupação das análises de Foucault, sobretudo para pensá-las como produtoras da subjetividade.

As análises arqueológicas e genealógicas são, também, algumas das narrativas que podem ser utilizadas para compreender a construção e a leitura foucaultiana, mas é na concepção ética do sujeito que Foucault entende estar seu problema central. "Não é, pois, o poder, mas o sujeito que constitui o tema geral de minhas pesquisas"11.

A estrutura analítica desse sujeito é fundamental para se perceber não só os efeitos devastadores de uma pandemia mundial, mas como a produção de informação sobre esse sujeito permite ao Estado o controle eficiente das políticas públicas para a população governada. Assim, aqui, parte-se de estudos de Foucault e de base foucaultiana ${ }^{12}$ a fim de discutir importantes temas como a governamentalidade e a biopolítica.

\subsection{A governamentalidade e a biopolítica de Michel Foucault, a alma governada de Nikolas Rose e a psicopolítica de Byung-Chul Han}

Nikolas Rose, em "Governando a alma: a formação do eu privado" enfatiza a importância das governanças do eu, o reconhecimento da subjetividade como objeto de mensuração e como categoria de análise exploratória. Segundo o autor, sob três aspectos, a saber: a regulação; a organização moderna (o mundo organizacional); e a expertise da

\footnotetext{
${ }^{10}$ FOUCAULT, Michel. Microfísica do poder. Rio de Janeiro: Paz e Terra, 2010. p. 12.

11 FOUCAULT, Michel. O sujeito e o poder. Ditos e Escritos - IX. Rio de Janeiro: Forense Universitária, 2014. p. 118-119.

12 ROSE, Nikolas. Governing the soul: the shaping of the private self. 2. Ed. Free Association Books, London/New York, 1999; HAN, Byung-Chul. Sociedade do cansaço. Petrópolis, RJ: Vozes, 2015 e HAN, Byung-Chul. Psicopolítica - o neoliberalismo e as novas técnicas de poder. Belo Horizonte: Editora Âyiné, 2018.

13 ROSE, Nikolas. Governing the soul: the shaping of the private self. 2. Ed. Free Association Books, London/New York, 1999. p. 01.
} 
subjetividade, os chamados "engenheiros da alma"14, revelam que as emoções têm sido emolduradas com objetivo especial de serem incorporadas aos intentos e aspirações dos poderes públicos. "Uma técnica que é centrada no corpo, produz efeitos individualizantes, manipula o corpo como foco de forças que é preciso tornar úteis e dóceis ao mesmo tempo. [...] que agrupa os efeitos de massas próprios de uma população". ${ }^{15}$

Nesse sentido, Rose entende a "governamentalidade" foucaultiana como sendo o “conjunto formado pelas instituições, procedimentos, análises e reflexões, os cálculos e as táticas, que permitem o exercício dessa forma muito específica, embora complexa, de poder e que tem como alvo a população" ${ }^{16}$. Assim, aproxima-se do conceito de Foucault, que brinda com uma história da governamentalidade.

O que gostaria de fazer agora seria alguma coisa que chamaria de "história da 'governamentalidade"'. Por essa palavra "governamentalidade", quero dizer três coisas. Por "governamentalidade", entendo o conjunto constituído pelas instituições, procedimentos, análises e reflexões, cálculos e táticas que permitem exercer essa forma bem específica, bem complexa, de poder, que tem como alvo principal a população, como forma mais importante de saber, a economia política, como instrumento técnico essencial, os dispositivos de segurança. Em segundo lugar, por "governamentalidade", entendo a tendência, a linha de força que, em todo o Ocidente, não cessou de conduzir, e há muitíssimo tempo, em direção à preeminência desse tipo de saber que se pode chamar de "governo" sobre todos os outros: soberania, disciplina. Isto, por um lado, levou ao desenvolvimento de toda uma série de aparelhos específicos de governo e, por outro, ao desenvolvimento de toda uma série de saberes. Enfim, por "governamentalidade", acho que se deveria entender o processo, ou melhor, o resultado do processo pelo qual o Estado de Justiça da Idade Média, tomado nos séculos XV e XVI Estado administrativo, encontrou-se, pouco a pouco, "governamentalizado"17.

Essa análise que Foucault produz sobre governamentalidade abarca um sentido bem mais amplo e que a compreende como arte de governar. Essas práticas de governamentalidade incluem não somente o governo de si, como bem explora Rose a partir das leituras de Foucault, mas, também, o governo dos outros, através das diferentes formas de cuidado de si, das disciplinas, da biopolítica e da razão de Estado ${ }^{18}$. No entanto, Foucault começa a mirar

\footnotetext{
${ }_{14}$ ROSE, Nikolas. Governing the soul: the shaping of the private self. 2. Ed. Free Association Books, London/New York, 1999. p. 33.

15 FOUCAULT, Michel. Em defesa da sociedade: curso do Collège de France (1975-1976). São Paulo: Martins Fontes, 2005. p. 235.

${ }^{16}$ ROSE, Nikolas. Governing the soul: the shaping of the private self. 2. Ed. Free Association Books, London/New York, 1999. p. 36.

${ }_{17}$ FOUCAULT, Michel. Microfísica do poder. Rio de Janeiro: Paz e Terra, 2010. p. 303.

18 CASTRO, Edgardo. Vocabulário de Foucault. Um percurso pelos seus temas, conceitos e autores. Belo Horizonte: Autêntica Editora, 2016. p. 191.
} 
historicamente no final do século XVII, e, assim, abre-se uma disruptiva em seus estudos com o aparecimento das tecnologias do poder disciplinar, que individualizam, classificam, vigiam e punem os indivíduos. ${ }^{19}$

De acordo com Foucault, entre os séculos XVIII e XIX, o modo pelo qual o poder começa a operar afeta a regulação da sociedade, potencializam-se outras divagações sobre o agir societário e, assim, o surgimento do conceito de biopolítica tem terreno fértil a prosperar. Esse termo cunhado pelo filósofo explicita a preocupação de Foucault com as formas de gestão da vida, não olhando mais para o indivíduo em si, mas sim para a população ${ }^{20}$. A biopolítica se apresenta como um ferramental potente a se referir ao conjunto de processos relacionados com a proporção de nascimentos e óbitos, a taxa de produção e a fecundidade de uma população, inclusive para auxiliar na compreensão das modelagens do Estado moderno e seus sentidos. Esse conceito de biopolítica serve (e serviu) de base para avanços teóricos como os apontados, por exemplo, por Agamben ${ }^{21}$.

Dessa forma, as práticas disciplinares utilizadas, que antes visavam governar o indivíduo, agora objetivam governar um conjunto de vidas e de indivíduos. A biopolítica assumese como mecanismo de monitoramento desse conjunto de indivíduos, que é a população. A biopolítica se constrói possibilitando práticas de biopoder de modo localizado. Nesse sentido, a vida não é mais vista em sua unidade. Portanto, as doenças não são mais problemas de saúde individuais, e sim sociais. O controle das doenças, dos nascimentos, dos óbitos serve como marcador para o governo produzir um maior controle sobre as populações governadas. Com isso, - Estado começa a cumprir outro papel: o higienista, de modo que a saúde pública, a coordenação de formas e mecanismos de tratamentos médicos, o fluxo e controle de dados (informações) e, sobretudo, a medicalização da população importa aos governos ${ }^{22}$.

Essas tecnologias de biopoder atribuem aos Estados uma relação de poder sobre a população. Esse poder é um poder-saber e uma forma de regulamentar a vida dos indivíduos.

19 FOUCAULT, Michel. Em defesa da sociedade: curso do Collège de France (1975-1976). São Paulo: Martins Fontes, 2005. p. 248.

20 FOUCAULT, Michel. Nascimento da Biopolítica: curso dado no Collège de France (1978-1979). São Paulo: Martins Fontes, 2008.

21 WERMUTH, Maiquel Ângelo Dezordi Wermuth; MORAIS, José Luis Bolzan de Morais. Da exceção agambeniana à constituição planetária de Ferrajoli: desafios impostos pela pandemia do novo coronavírus às categorias jurídico-políticas tradicionais. Revista Eletrônica do Curso de Direito da UFSM, v. 15, p. 1 29, 2020. Disponível em: https://periodicos.ufsm.br/revistadireito/article/view/43057. Acesso em: 02 ago. 2020.

22 FOUCAULT, Michel. Nascimento da Biopolítica: curso dado no Collège de France (1978-1979). São Paulo: Martins Fontes, 2008. p. 167. 
Embora, em alguns textos de Foucault ${ }^{23}$, quando se refere à biopolítica, apareça a palavra morte, o que the interessava era o cuidado com a vida. Importa dizer que esse poder-saber se traduzia por meio do controle do corpo, estudado especialmente pela disciplina. "Uma 'anatomia política', que é também igualmente uma 'mecânica do poder' [...] A disciplina fabrica assim corpos submissos e exercitados, corpos 'dóceis'”24. Dessa forma, Foucault articula biopolítica, poder e corpo (vida e morte) ao império da lei e ao Estado.

Pode-se afirmar a partir do ferramental foucaultiano, que a disciplina se liga ao corpo, individualiza-o, tratando-o como organismo por meio das chamadas instituições de sequestro (escola, quartel, hospício, prisão). Por outro lado, a biopolítica trata da população, mas não como organismo, e sim como processos biológicos e de cuidado da vida de interesse do Estado. ${ }^{25}$

Por esse viés, Foucault entende que essas expertises objetivam "governar os sujeitos"26 para o que desempenham papel determinante na domesticação dos mesmos, já que o conhecimento (dados, números, fenômenos...) gera a possibilidade de mensurar os fins sóciopolíticos das subjetividades: o educar, o curar, o reformar e o punir ${ }^{27}$. Esse domínio do conhecimento, explica Rose, permite combinar o "exercício da vigilância, a aplicação do julgamento normalizador e a técnica da inscrição material”. ${ }^{28}$ Nesses entrecruzamentos, o governo opera sobre a subjetividade, tornando-a calculável e possibilitando, assim, uma técnica autorregulatória de cunho preponderantemente psicológico capaz de mapear todos os nossos “eus privados".

De acordo com Rose, ao produzir conhecimentos positivos, possíveis reivindicações de verdade, as ciências (especialmente o campo $\mathrm{psi}^{29}$ ) estabelecem formas de "governar" os sujeitos sob o ponto de vista dessas práticas e aparelhos, de maneira que parecem estar baseadas, não em autoridade arbitrária, mas em uma natureza real dos seres humanos como sujeitos psicológicos. ${ }^{30}$

${ }^{23}$ FOUCAULT, Michel. Nascimento da Biopolítica: curso dado no Collège de France (1978-1979). São Paulo: Martins Fontes, 2008. p. 211.

${ }^{24}$ FOUCAULT, Michel. Vigiar e punir. Petrópolis, RJ: Vozes, 2014.

25 FOUCAULT, Michel. Em defesa da sociedade: curso do Collège de France (1975-1976). São Paulo: Martins Fontes, 2005.

${ }^{26}$ ROSE, Nikolas. Governing the soul: the shaping of the private self. 2. Ed. Free Association Books, London/New York, 1999. p. 36.

27 ROSE, Nikolas. Governing the soul: the shaping of the private self. 2. Ed. Free Association Books, London/New York, 1999. p. 38.

${ }^{28}$ ROSE, Nikolas. Governing the soul: the shaping of the private self. 2. Ed. Free Association Books, London/New York, 1999. p. 39.

${ }_{29}$ Psicologia, Psicanálise e Psiquiatria.

${ }^{30}$ ROSE, Nikolas. Governing the soul: the shaping of the private self. 2. Ed. Free Association Books, London/New York, 1999. 
Nesse sentido, no entendimento de Rose, as ciências humanas e sociais tornam possível o exercício da autoridade política, moral, organizacional e pessoal de maneira compatível com as noções do Estado Liberal, fulcrado basicamente na liberdade e na autonomia dos indivíduos. Para Rose, é fundamental distinguir a existência de quatro áreas de ação sobre este "eu": o governo de forças militares e civis em tempos de guerra; a regulamentação da fábrica e da vida econômica; o desenvolvimento de novas formas de entender e intervir no desenvolvimento de crianças, adolescentes e nas relações familiares; e, por último, no crescimento vertiginoso da influência das ciências "psi”. ${ }^{31}$

Segundo Rose ${ }^{32}$, existe (nos moldes como pensava Foucault) uma fabricação da vida. Assim, fabricam-se sujeitos (homens e mulheres) capazes de suportar os encargos da liberdade nas formas de vida ocidentais contemporâneas. Sujeitos "psi” que passam a celebrar valores de autonomia e autorrealização em um contexto neoliberal ${ }^{33}$. "Ser livre, portanto, não significa nada mais do que se realizar conjuntamente. Liberdade é sinônimo de comunidade bemsucedida" ${ }^{34}$. De acordo com Rose ${ }^{35}$, a persuasão passa a ser a medida exata (a dose indicada) para que o sujeito cidadão possa ser gradativamente institucionalizado, já que, assim, o governo contemporâneo conseguirá, sutilmente, através das “técnicas do eu" 36 , buscar a essência da “alma” para sua posterior administração e regulação.

É o que argumenta Han, ao afirmar que vivemos um capitalismo da emoção. "A psicopolítica neoliberal se ocupa da emoção para influenciar ações sobre esse nível préreflexivo. As pessoas são profundamente atingidas [...] ela representa meio muito eficiente de controle psicopolítico do indivíduo". ${ }^{37}$ Essa psicopolítica neoliberal fomenta formas de exploração do eu, a partir de mecanismos de gestão pessoal, coaching motivacional, aumento da eficiência sem limites, gerando cansaço e esgotamento. “Como contraponto, a sociedade do

31 ROSE, Nikolas. Governing the soul: the shaping of the private self. 2. Ed. Free Association Books, London/New York, 1999.

32 ROSE, Nikolas. Governing the soul: the shaping of the private self. 2. Ed. Free Association Books, London/New York, 1999.

${ }^{33}$ HAN, Byung-Chul. Psicopolítica - o neoliberalismo e as novas técnicas de poder. Belo Horizonte: Editora Âyiné, 2018. p. 11.

${ }^{34}$ HAN, Byung-Chul. Psicopolítica - o neoliberalismo e as novas técnicas de poder. Belo Horizonte: Editora Âyiné, 2018, 2018. p. 12.

35 ROSE, Nikolas. Governing the soul: the shaping of the private self. 2. Ed. Free Association Books, London/New York, 1999. p. 42.

${ }^{36}$ ROSE, Nikolas. Governing the soul: the shaping of the private self. 2. Ed. Free Association Books, London/New York, 1999. p. 43.

${ }^{37}$ HAN, Byung-Chul. Psicopolítica - o neoliberalismo e as novas técnicas de poder. Belo Horizonte: Editora Âyiné, 2018. p. 68. 
desempenho e a sociedade ativa geram um cansaço e esgotamento excessivos. 0 excesso de elevação do desempenho leva a um enfarto da alma”. ${ }^{38}$

Talvez na contemporaneidade, e diante das possibilidades de esgaçamento conceitual, seja possível falar em uma biopsicopolítica baseada nas tessituras entre Foucault e Han. Admitindo-se que essas governanças do eu (de si) nos (re)produzem enquanto sujeitos controlados pelos big data, num sistema altamente complexificado de reconhecimento e assujeitamento de nossos corpos (cada vez mais precários) com vias a transformar o sujeito cidadão em um cidadão consumidor. Um espectador passivo diante de inúmeros aparatos digitais (computador, smartphone), que produzem vigilância, controle e conhecimento de si (contra si).

\subsection{Vida precária em Butler}

Se certas vidas não são qualificadas como vidas ou se, desde o começo não são concebíveis como vidas de acordo com certos enquadramentos epistemológicos, então essas vidas nunca serão vividas nem perdidas no sentido pleno dessas palavras. $^{39}$

Como é possível mensurar o que é passível de luto? Que vida merece ser chorada? O que seria uma concepção de vida boa ou de vida chorável? ${ }^{40}$ "En el criterio con que juzgamos qué vidas tienen derecho a ser vividas, se hace evidente que la desigualdad social desempeña un papel muy importante en nuestro modo de abordar la cuestión de qué vidas merecen ser lloradas" ${ }^{41}$. Essas e tantas outras perguntas que faz Butler permitem questionar sobre a fragilidade da vida, sobre o luto e a morte. Butler nos indaga sobre as múltiplas formas de levar uma vida boa dentro de um conjunto de "vidas ruins". Para tentar apontar uma resposta, seria importante delimitar se é possível, nos moldes aristotélicos, definir o que é uma vida boa.

Butler procura dar ao aparecimento alguns temas que devem (ou deveriam) prescindir uma conceptualização de boa vida. Para a autora, sobretudo nos campos da ética, da política e da resistência, surgem alguns elementos capazes de refletir sobre o fato de que as possibilidades de uma vida boa só podem existir para alguns, vale dizer, em que medida a minha vida boa

\footnotetext{
${ }^{38}$ Han, Byung-Chul. Psicopolítica - o neoliberalismo e as novas técnicas de poder. Belo Horizonte: Editora Âyiné, 2018. p. 71.

39 BUTLER, Judith. Cuerpos que importan: sobre los limites materiales y discursivos del "sexo". Buenos Aires, Argentina: Paidós, 2012, p. 13.

40 Tradução livre de BUTLER, Judith. Qu'est-ce qu'une vie bonne? Éditions Payot \& Rivages, Paris, France, 2014.

${ }^{41}$ BUTLER, Judith. Sin miedo: Formas de resistencia a la violencia de hoy. Penguin Random House Grupo Editorial España. Edição do Kindle, 2020, p. 276.
} 
requer o sofrimento dos outros, a negação de suas próprias vidas, e de que forma, dentro deste paradigmático conceito, isso pode ser chamado de vida boa ${ }^{42}$ Nos termos delimitados por Butler, ter ou não ter uma vida boa apresenta uma potente crítica exercida contra um poder centrado, em regra pelo Estado, que governa os sujeitos na precarização e na negação da vida. Esta crítica assinada por Butler, em inúmeros de seus estudos, inclusive na sua mais recente obra $^{43}$, expõe a realidade presente.

Butler procura dar significados à urgente necessidade de construir um novo presente. Para a filósofa, esse novo presente exige uma redefinição nas práticas entre a ética, a moral e a política. Pensar as condições de vida humana, segundo Butler, é entender as formas como se constroem as precariedades e as vulnerabilidades, a que boa parte dos sujeitos estão expostos. Para tal, é fundamental perceber a qualidade (ou a negação) a que a própria vida está subordinada. De acordo com Butler ${ }^{44}$, não é possível crer numa vida que seja totalmente boa, sem sopesar a vida.

Pues si una vida se considera carente de valor, si una vida puede destruirse o hacerse desaparecer sin dejar rastro o consecuencias aparentes, eso significa que esa vida no se concebía plenamente como viva y, por tanto, no se concebía plenamente como llorable. ${ }^{45}$

O conteúdo ético imposto aos sujeitos dentro de uma premente vida boa implica na observância de posturas civilizatórias que questionem as estratégias e os mecanismos de poder, de opressão e de violência para que algumas vidas sejam boas e outras não. Impõe-se, também, perscrutar quais vidas realmente importam? Como já fez Butler em outra de suas produções acadêmicas. É possível que tenham vidas de "maior valor”? Como aferir nestes termos? “Assim, a precariedade, a abjeção, a vulnerabilidade social e a subalternização das vidas são orientadas pelo discurso que impõe, marca e qualifica o humano do inumano" ${ }^{46}$. Concordando com Butler ${ }^{47}$

\footnotetext{
${ }^{42}$ BUTLER, Judith. Qu'est-ce qu'une vie bonne? Éditions Payot \& Rivages, Paris, France, 2014, p. 68.

${ }^{43}$ BUTLER, Judith. Sin miedo: Formas de resistencia a la violencia de hoy. Penguin Random House Grupo Editorial España. Edição do Kindle, 2020.

${ }^{44}$ BUTLER, Judith. Qu'est-ce qu'une vie bonne? Éditions Payot \& Rivages, Paris, France, 2014. p. 76.

45 BUTLER, Judith. Sin miedo: Formas de resistencia a la violencia de hoy. Penguin Random House Grupo Editorial España. Edição do Kindle, 2020. p. 276.

${ }^{46}$ DIAS, Renato Duro e BRUM, Amanda Netto. (Re) significando o discurso dos direitos humanos: um diálogo a partir da educação em e para os direitos humanos. Revista Quaestio iuris. vol. $10, \mathrm{n}^{\circ}$. 04 , Rio de Janeiro, 2017. $\quad$ p. 2402. Disponível em: https://www.epublicacoes.uerj.br/index.php/quaestioiuris/article/view/25690. Acesso em: 02 ago. 2020.

47 KADNER, Marién. Judith Butler: "Matar é o ápice da desigualdade social”. Filósofa norte-americana, alvo de protestos no Brasil no ano passado por sua teoria sobre gênero, prepara uma nova obra sobre a ética da
} 
“Aceitamos que todos aqueles que são privados da vida através da violência sofrem uma injustiça radical”, “matar é o ápice da desigualdade social”. Alguns corpos, portanto, são merecedores de luto e outros não.

Como bem lembra Butler, a igualdade não é uma condição natural, mas social; portanto, a tarefa que se impõe é traduzi-la na concretude do imaginário social, construindo-a eticamente, de modo a vincular uma vida a outra. Em Vidas Precárias ${ }^{48}$ e Corpos que importam ${ }^{49}$, Butler afirma que é igualmente verdadeiro que uma dada propriedade ou um conjunto de características do corpo dependam da persistência continuada do corpo, em uma determinada posição de submissão, abjeção ou vulnerabilidade. "A precariedade se traduz numa subordinação das condições políticas do sujeito-humano [...] São corpos que importam menos, vidas precárias que se submetem, diariamente, às injustiças e às indignidades". ${ }^{50}$

Tais condições de manifestação de performatividade se traduzem como uma forma de reivindicar direito a que estes corpos performativos deveriam ter acesso. Para Butler, a precariedade é distribuída desigualmente, o que acarreta num conjunto de iniquidades e desequilíbrios, tornando algumas vidas mais vulneráveis que outras. Somos todos precários, nos questiona Butler ${ }^{51}$, mas alguns estão em condições mais precárias que outros e dizer o contrário seria uma imensa irresponsabilidade. Butler nos indaga, somos todos humanos? Mas por que nossa dor e luto se dirigem a alguns? Quem e o que conta para nossos critérios de humanidade? Que vida merece viver? Que vida merece ser tratada como humana? Pois bem, isto estabelece a exposição e a precariedade e, deste modo, adentram a própria ação (revolucionária) de aparecimento (estar em) público (coletivamente). A exposição desses corpos no espaço público é em essência aquilo que os constitui enquanto pensamento político e social. É dessa forma que Butler percebe a visibilidade e a resistência coletiva.

Segundo Butler ${ }^{52}$, constituindo-se de perspectivas, desejos, vocalizações, questões materiais e outras expressões de necessidade (fome, frio, pulsão) que fazem emergir, dentre tantas urgências, o reconhecimento ao espaço público “onde a legitimidade do Estado é

não violência. El País. Caderno de Cultura. 27 nov. 2018. Disponível em: https://brasil.elpais.com/brasil/2018/11/27/cultura/1543350943_401404.html. Acesso em: 09 abr. 2020.

${ }_{48}$ BUTLER, Judith. Vida precaria: el poder del duelo y la violencia. Buenos Aires, Argentina: Paidós, 2009.

49 BUTLER, Judith. Cuerpos que importan: sobre los limites materiales y discursivos del "sexo". Buenos Aires, Argentina: Paidós, 2012.

50 DIAS, Renato Duro; BRUM, Amanda Netto. (Re) significando o discurso dos direitos humanos: um diálogo a partir da educação em e para os direitos humanos. Revista Quaestio iuris. vol. 10, $\mathrm{n}^{\circ}$. 04, Rio de Janeiro, 2017. $\quad$ p. 2397. Disponível em: https://www.epublicacoes.uerj.br/index.php/quaestioiuris/article/view/25690. Acesso em: 02 ago. 2020.

${ }^{51}$ BUTLER, Judith. Vida precaria: el poder del duelo y la violencia. Buenos Aires, Argentina: Paidós, 2009.

${ }^{52}$ BUTLER, Judith. Cuerpos aliados y lucha política. Buenos Aires, Argentina: Paidós, 2017. 
colocada em questão precisamente por essa maneira de aparecer em público, o próprio corpo exerce um direito que não é um direito" 53 . O direito ao aparecimento se manifesta como uma estratégia performativa de garantir direitos.

\section{A COVID-19 NO BRASIL: DIÁLOGOS NECESSÁRIOS PARA O AMANHÃ}

A pandemia de COVID-19 no Brasil tem representado um dos grandes desafios para o Estado Democrático de Direito, alicerçado, fundamentalmente, na Constituição Federal de 1988. Seja pela dimensão territorial, seja pela dificuldade de articulação entre diversos atores sociais ou a concorrente competência entre os entes federados em matéria de saúde pública, o período de emergência tem se configurado, assim, em um intrincado processo que demarca uma trágica etapa historiográfica para a República brasileira.

Quando se trata de analisar, especialmente, o papel do Estado brasileiro sob a perspectiva foucaultiana, tendo como recorte a "arte de governar" em matéria de saúde coletiva, o que se percebe é uma dificuldade justamente no plano coletivo e nas formas como a política se consolida como uma verdadeira experiência pública. A total ausência de uma diretriz pelo governo central, acumulada pela alternância nos principais cargos de gestão no Ministério da Saúde implicaram em uma baixa performatividade de governança e na inexpressiva capacidade de articulação entre as demais esferas. Essa governamentalidade se tornou ainda mais complexa diante dos quadros que emolduram as condições desigualizantes, perpetradas pelo neoliberalismo vigente.

É importante frisar que Foucault produziu seu conceito de governamentalidade a partir de outros marcadores históricos, que configuravam o estado liberal com certas diferenças ao que contemporaneamente denominamos de estado neoliberal. No entanto, parece que as racionalidades e as tecnologias governamentais apresentadas por Foucault ao longo de suas conferências permitem inferir a mesma necessidade de conduzir os corpos populacionais para a manutenção do Estado, mesmo diante de uma governamentalidade neoliberal.

Parece absolutamente paradoxal que o cuidado com a vida e com a população, conforme descrito por Foucault em várias passagens de seus escritos, se transformem em estratégia de racionalizar ainda mais o Estado (razão de Estado). No entanto, essa política de governar serve como elemento solidificador do próprio Estado, dando a ele um papel de polícia,

${ }^{53}$ BUTLER, Judith. Cuerpos aliados y lucha política. Buenos Aires, Argentina: Paidós, 2017. p. 86. 
que de um lado suplementa (garante) a vida da população e de outro reforça o poder do próprio Estado. Eis, aqui, o Estado como fim último.

Um elemento determinante relacionado à governamentalidade do Estado brasileiro e que reverbera sobre a conceptualização biopolítica foucaultiana é traduzido através da ciência estatística. Ferramental muito explorado por Foucault, o conjunto de dados estatísticos foi sempre a base para entender as estratégias de regulação do biopoder. Portanto, no contexto pandêmico, os dados podem elucidar a gestão dos corpos e a garantia ou não de suas existências.

Os dados e estudos epidemiológicos sobre a ascendência da curva no Brasil (ou mesmo sua manutenção sob a forma de platô) apontam os impactantes números do Coronavírus no território brasileiro e revelam, sobretudo, a ineficácia da gestão da saúde pública pelo governo central. De acordo com o último boletim divulgado pelo Ministério da Saúde (Quadro 2), o país conta com mais de dois milhões e setecentos mil casos notificados, soma aproximadamente noventa e três mil e quinhentas mortes e uma taxa de letalidade de três e meio por cento. Por outro lado, surge como relevante o dado de um milhão e oitocentas mil pessoas como casos recuperados.

Quadro 2 - Painel Coronavírus no Brasil

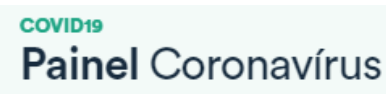

Atualizado em: 01/08/2020 18:30

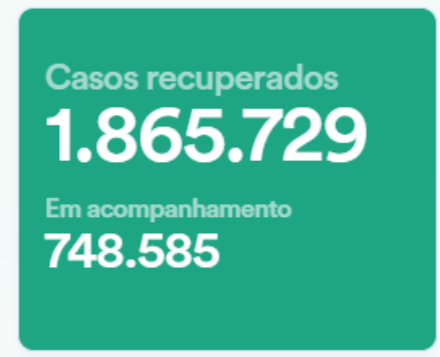

Fonte: Ministério da Saúde, $2020^{54}$.
CASOS CONFIRMADOS

2.707.877 45.392 Acumulado Casos novos 1288,6

Incidēncia*
ÓBITOS CONFIRMADOS

$93.563 \quad 1.088$

Obitos acumulados Casos novos

$3,5 \% \quad 44,5$

Letalidade Mortalidade*

Paralelamente, a dificuldade de produzir orientações sanitárias confiáveis, a falta de recursos e o certo atraso em disseminar informações no território nacional têm levado o Ministério da Saúde a operar sob a égide de um desregramento vertical, inclusive se

${ }^{54}$ MINISTÉRIO DA SAÚDE. Painel Coronavírus. Disponível em: https://covid.saude.gov.br/. Acesso em: 05 ago. 2020. 
manifestando em desacordo com os protocolos estabelecidos pela Organização Mundial de Saúde. No mesmo sentido, o governo central opta por se adaptar a um baixo número de testagens, dificultando a estimativa real da pandemia.

Recente estudo divulgado dimensionou que cerca de oito por cento (8\%) dos casos são notificados, indicando que o número de casos poderia ser doze (12) vezes maior. "Os resultados, ainda que preliminares, indicam que no Brasil as notificações são de apenas $8,0 \%$ (7,8\% - 8,1\%) dos casos de COVID-19 [...] Isso indicaria que o número real de casos no Brasil é cerca de 12 vezes maior que o oficialmente reportado. ${ }^{55} 0$ número de casos confirmados não opera dentro das cifras previstas, conferindo o problema da subnotificação. “O elevado grau de subnotificação pode sugerir uma falsa ideia de controle da doença e, consequentemente, poderia levar ao declínio na implementação de ações de contenção, como o isolamento horizontal". ${ }^{56}$

Figura 2 - Casos de COVID-19 por Município de notificação.

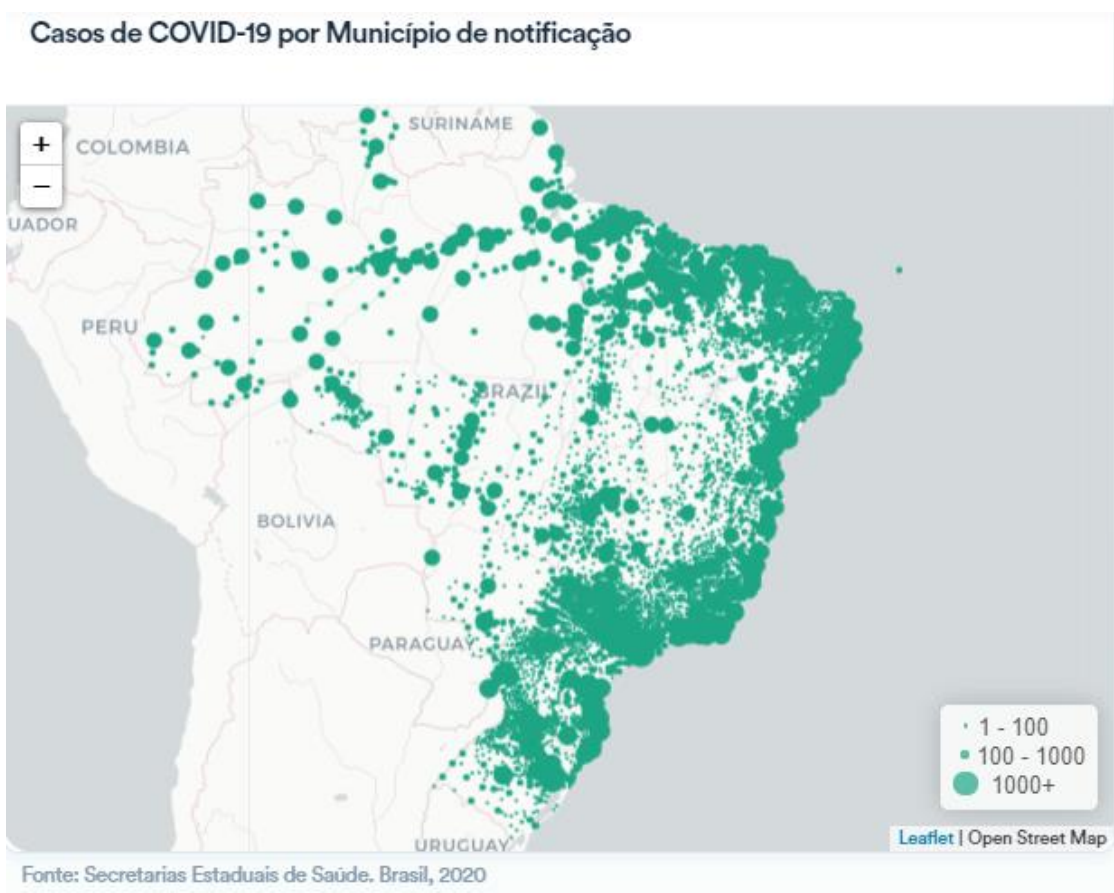

Fonte: Ministério da Saúde, $2020^{57}$.

\footnotetext{
${ }^{55}$ NOIS. Núcleo de Operações e Inteligência em Saúde. Inteligência computacional aplicada à predição da evolução da COVID-19 e ao dimensionamento de recursos hospitalares. Disponível em: https://drive.google.com/file/d/1_whlqZnGgvqHuWCG4-JyiL2X9WXpZAe3/view Acesso em: 02 ago. 2020. ${ }^{56}$ NOIS. Núcleo de Operações e Inteligência em Saúde. Inteligência computacional aplicada à predição da evolução da COVID-19 e ao dimensionamento de recursos hospitalares. Disponível em: https://drive.google.com/file/d/1_whlqZnGgvqHuWCG4-JyiL2X9WXpZAe3/view Acesso em: 02 ago. 2020. ${ }_{57}$ MINISTÉRIO DA SAÚDE. Painel Coronavírus. Disponível em: https://covid.saude.gov.br/. Acesso em: 05 ago. 2020.
} 
Figura 3 - Óbitos de COVID-19 por Município de notificação.

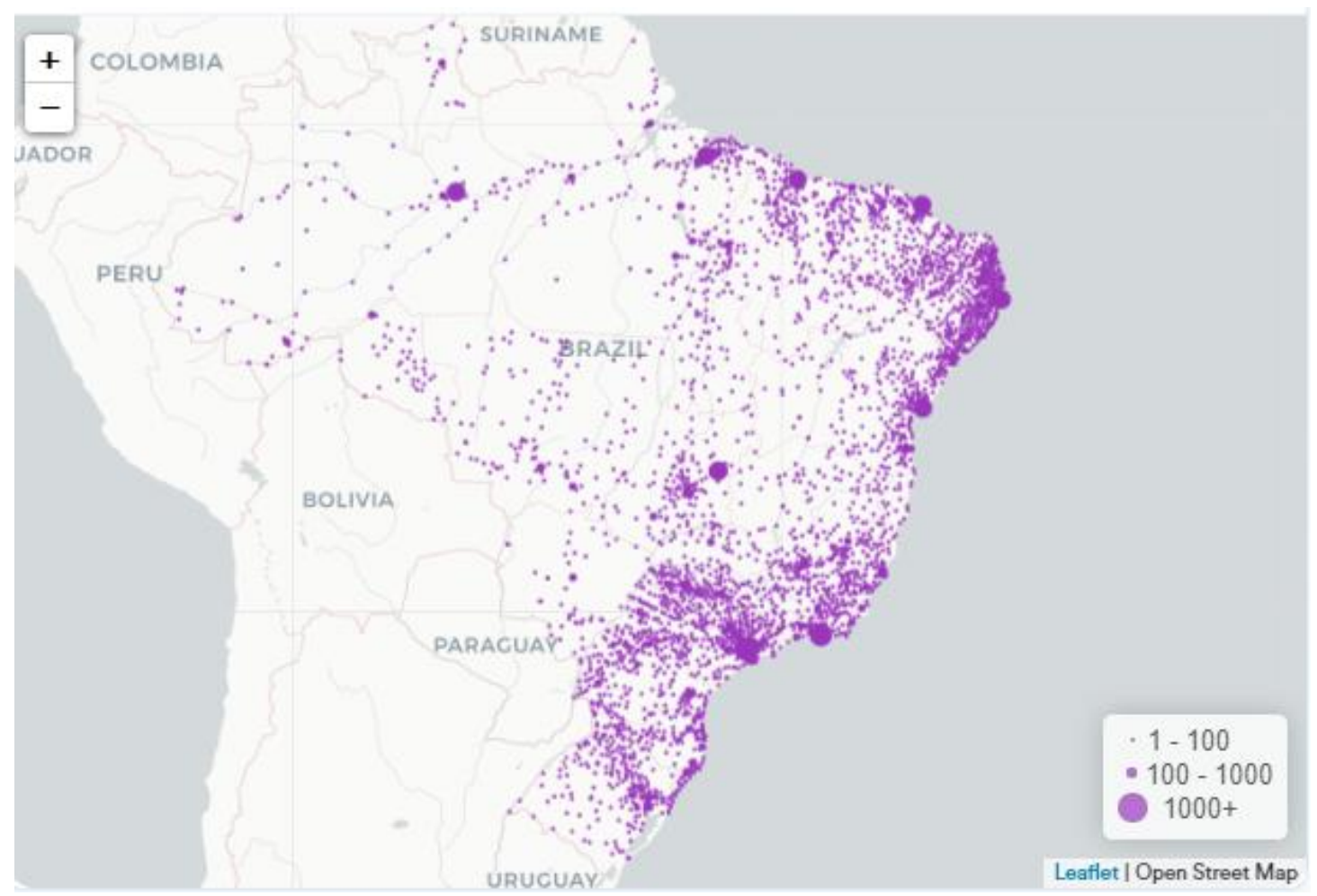

Fonte: Ministério da Saúde, $2020^{58}$.

Estes dados refletem parte dos efeitos da pandemia no governo das vidas. “Governam-se coisas. Mas o que significa esta expressão? Não creio que se trate de opor coisas a homens, mas de mostrar os homens [...] em suas relações com outras coisas ainda que podem ser os acidentes ou as desgraças como a fome, a epidemia, a morte, etc". ${ }^{59}$ As emergências de raça e classe apontam para uma triste contabilidade estatística.

A explosão de casos de negros que são hospitalizados ou morrem por Covid-19 tem escancarado as desigualdades raciais no Brasil: entre negros, há uma morte a cada três hospitalizados por SRAG causada pelo coronavírus; já entre brancos, há uma morte a cada 4,4 hospitalizações.

${ }^{58}$ MINISTÉRIO DA SAÚDE. Painel Coronavírus. Disponível em: https://covid.saude.gov.br/. Acesso em: 05 ago. 2020.

59 FOUCAULT, Michel. O sujeito e o poder. Ditos e Escritos - IX. Rio de Janeiro: Forense Universitária, 2014. p. 282. 


\section{Mortes por Covid-19 no Brasil crescem mais entre negros}

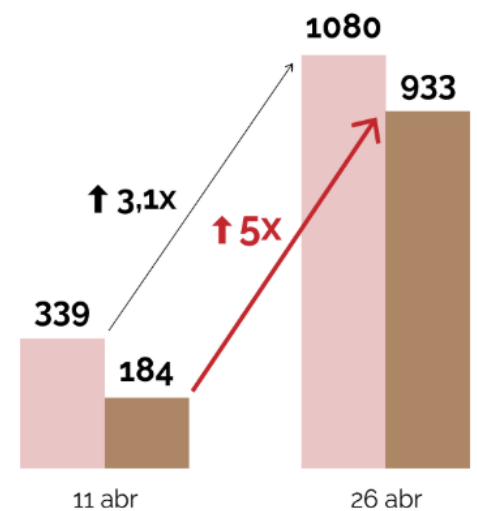

Os dados são resultado de uma análise feita pela Agência Pública ${ }^{60}$ com base nos boletins epidemiológicos do Ministério da Saúde que possuem informações de raça e cor de internações e mortes por coronavírus. O Governo Federal divulgou esses números atualizados apenas até 26 de abril.

A supressão desses dados, de modo a relativizar a importância de determinadas vidas, evidencia os sentidos em que os termos governamentalidade, biopolítica e vida precária se inscrevem na escritura corporal da realidade populacional brasileira.

Las poblaciones se dividen a menudo, demasiado a menudo, entre aquellos cuyas vidas son dignas de protegerse a cualquier precio y aquellos cuyas vidas se consideran prescindibles. Dependiendo del género, de la raza y de la posición económica que ostentemos en la sociedad, podemos sentir si somos más o menos llorables a ojos de los demás. ${ }^{61}$

Somados a esse conjunto de dados, que por vezes se digladiam entre declarações públicas dos governantes ${ }^{6263}$ e estudos ${ }^{6465}$ científicos, existe uma gama de elementos que ronda o

60 MUNIZ, Bianca; FONSECA, Bruno; PINA, Rute. Em duas semanas, número de negros mortos por coronavírus é cinco vezes maior no Brasil. Publica, 06 maio 2020. Disponível em: https://apublica.org/2020/05/em-duas-semanas-numero-de-negros-mortos-por-coronavirus-e-cinco-vezesmaior-no-brasil/. Acesso em: 02 ago. 2020.

${ }^{61}$ BUTLER, Judith. Sin miedo: Formas de resistencia a la violencia de hoy. Penguin Random House Grupo Editorial España. Edição do Kindle, 2020. p. 288.

62 ESTADÃO CONTEÚDO. No Twitter, Bolsonaro compartilha vídeo criticando isolamento social. Exame, 11 abr. 2020. Disponível em: https://exame.com/brasil/no-twitter-bolsonaro-compartilha-video-criticandoisolamento-social/. Acesso em: 05 ago. 2020. 
cotidiano discursivo e que em um momento de tensão pela pandemia do COVID-19 se tornam um complicador no contexto nacional.

De outra banda, figuram, de um lado, os discursos veiculados em favor do isolamento social, em defesa do Sistema Único de Saúde (SUS), da ciência (e com isso a relevância das pesquisas e os investimentos em educação pública de qualidade, especialmente realizada nas universidades federais); e, de outro lado, o desmonte dos sistemas de seguridade pública e suas consequentes políticas públicas, o descrédito na ciência e um aceno ao histerismo profético.

A maioria destes discursos está ligada a um sistema jurídico-institucional que produz "verdades" e que sobre todas as formas rodeia, determina e articula a produção de novos discursos. É importante que se diga, especialmente em tempos de Instagram, Whatsaspp, Facebook e Twitter, que os discursos são objetos de apropriação e de manipulação. Dentro da perspectiva foucaultiana, é a apropriação de um discurso pelo autor que o permite poder falar e ser ouvido e isso é concretizado de um não lugar ${ }^{66}$. Por isso, é possível dizer que a classificação e o controle atuam sobre o sujeito na medida em que os discursos dão voz e autoria, especialmente na produção e na construção de um homo oeconomicus. ${ }^{67}$

A construção desse sujeito "homem econômico", por dentro de um Estado Liberal, segundo Foucault, serviu de sustentação para uma governamentalidade que moldou sua intervenção na racionalidade dos próprios sujeitos (da população) em favor do Estado. Essa operação criou tensões e clivagens que afetaram o próprio governo das vidas. Talvez este seja um dos problemas temporais pelos quais Foucault não tivesse imaginado: o sujeito liberal (neoliberal) imbuído de seus fins econômicos não possui garantia de vida.

A palavra de ordem "gerenciar" a vida traduz o código de troca econômico. Nesse cenário, morrer e adoecer são termos que carregam consigo a marginalização e a consequente exclusão. No entanto, é essa a mesma sociedade que produz cansaço, esgotamento e morte. Eis o dilema, "governar" a vida ou "deixar" morrer.

${ }^{63}$ OHARA, Victor. MPF processa governo por campanha de Bolsonaro pelo fim do isolamento. Carta Capital Saúde. 6 abr. 2020. Disponível em: https://www.cartacapital.com.br/saude/mpf-processa-governo-porcampanha-de-bolsonaro-pelo-fim-do-isolamento/. Acesso em: 02 ago .2020.

${ }^{64}$ FREITAS, André Ricardo Ribas; NAPIMOGA, Marcelo; DONALISIO, Maria Rita. A análise da gravidade da pandeia de COVID-19. Disponível em: http://www.scielo.br/scielo.php?script=sci_arttext\&pid=S223796222020000200900. Acesso em: 02 ago. 2020.

65 TESINI, Brenda T. Coronavírus e síndromes respiratórias agudas (COVID-19, MERS e SARS). Disponível em: $\quad$ https://www.msdmanuals.com/pt-pt/profissional/doen\%C3\%A7as-infecciosas/v\%C3\%ADrusrespirat\%C3\%B3rios/coronav\%C3\%ADrus-e-s\%C3\%ADndromes-respirat\%C3\%B3rias-agudas-covid-19,-mers-esars\#v47572272_pt. Acesso em: 02 ago. 2020.

${ }^{66}$ FOUCAULT, Michel. As palavras e as coisas. São Paulo: Martins Fontes, 2007. p. 184.

67 Para o conceito ver: FOUCAULT, Michel. Nascimento da Biopolítica: curso dado no Collège de France (1978-1979). São Paulo: Martins Fontes, 2008. 
Esses dilemas contemporâneos vividos pela população brasileira, amalgamados pela crise sanitária que lhes afeta, produzem fissuras no tecido social que não serão menores do que as vidas que forem perdidas ao longo desse tempo histórico. Para tentar finalizar em sede de considerações finais, pretende-se retomar a questão central que parece ser fundamental. Em que medida os estudos de Michel Foucault, Judith Butler, Byung-Chul Han e Nikolas Rose reverberam sobre nossas emergências?

\section{CONCLUSÃO}

A biopolítica foucaultiana assume um papel relevantíssimo na análise de um modelo de desenvolvimento neoliberal como o aplicado no Brasil. Ela é capaz de produzir significados no sentido de configurar a implementação de uma estrutura bioeconômica, cuja matriz principal seria criar uma governança econômica de vidas. A biopolítica exercida na contemporaneidade a partir da produção do homo oeconomicus potencializa, assim, a governamentalidade das vidas sob a égide de um Estado ausente e incapaz de distribuir riquezas e minimizar as desigualdades. Num contexto como o brasileiro, a precarização das vidas seria maximizada.

Conforme alerta Han, no capitalismo imaterial, a comunicação, a informação, a criatividade e a performatividade atribuem valor ao sujeito, ao ponto de se falar numa "virada linguística econômica". Nestes termos, produzir, comunicar e ser criativo, e a partir daí estabelecer relações, podem ser considerados os verbos da subserviência ao processo de valorização capitalista. Num estado como o brasileiro, no qual relações entre empregador e empregado são tão díspares, com legislação laboral altamente flexível e um elevado grau de informalidade, a pandemia de COVID-19 tende a colocar nas ruas um conjunto de vidas sem perspectiva alguma.

Conforme Rose, as gestões do corpo e da psique (governo da alma) são potentes ferramentas para acelerar os processos de subjetivação, que tornam os sujeitos cada vez mais produtivos, criativos, "senhores de si". Esse caminho, traçado pela massificação e pela terceirização das relações gera um sujeito que ao mesmo tempo é servo e senhor.

Como assevera Han, a sociedade neoliberal não está mais preocupada com o sujeito, agora o centro é o projeto. Vive-se pensando em (novos) projetos individuais, à espera que, em fracassando, venham outros tantos em seu lugar. A pandemia de COVID-19, nesses termos, escancarou (mundialmente) a quantidade de "projetos" frustrados e a precariedade de quem não pode se isolar socialmente, pois no outro dia não terá o que comer. No Brasil, em todas as 
regiões, em grandes ou pequenas cidades, visualizam-se infindáveis filas de pessoas jogadas à sorte de auxílios emergenciais.

As novas subjetivações almejam um corpo melhor (perfeito), saúde e, sobretudo, uma obrigação de estar saudável, veja-se a moda fitness. Assim, acrescidas às preocupações individuais por "estar bem” (saudável), as governanças têm como razão de Estado produzir (financiar) instrumentos e sistemas que cuidem da saúde coletiva. No entanto, nas economias de mercado em que o neoliberalismo predatório atua, como é o caso Brasil, o investimento em saúde pública, a criação de estratégias de saúde e a organização de um sistema de saúde público robusto se transformam em "gasto", "peso para o estado" ou entrave para a mercantilização da saúde (das vidas). Aqui reside outro grande desafio.

A ação do Ministério da Saúde em regime de compartilhamento, como estabelece o Sistema Único e a Constituição Federal, aponta que o modelo institucional proposto para o SUS foi ousado no que concerne à tentativa de concretizar um arranjo federativo na área da saúde pública. $O$ desafio dado é o de fortalecer o controle social sobre as políticas, de forma coerente com os princípios e as diretrizes do Sistema Único de Saúde. "O SUS é o eixo da resposta brasileira, é nossa única e grande esperança"68.

O contexto nos indaga, quais vidas importam? Que vida merece viver? Por que alguns corpos merecem reconhecimento (direitos) e outros não? Em um momento de grande complexidade em que se busca enfrentar a pandemia de COVID-19 no Brasil, talvez nunca seja demasiado repetir que a precarização e flexibilização de direitos, nos moldes como está em curso, somente acelerará os processos de exclusão e de produção de mais desigualdades.

Também importa reforçar o coro de vozes na defesa de um sistema de saúde público e gratuito, alcançável a todas e todos. E, por fim, reafirmar: todas as vidas importam. "Tu vida importa, se trata de un principio en el que residen la organización social de la sanidad, la alimentación, el techo, el empleo, la educación, la vida sexual, la vida social y cívica”. ${ }^{69}$

Por fim, em que medida os conceitos de vida precária, biopolítica e governamentalidade podem desvelar o contexto da pandemia de COVID-19 no Brasil? Entende-se que o ferramental apresentado a partir das escritas de Michel Foucault, Judith Butler, Byung-Chul Han e Nikolas Rose reverberam sobre as emergências e contribuem para pensar a contemporaneidade,

68 VENTURA, Deisy. Entrevista especial com Deisy Ventura. [Entrevista cedida a] João, 23 mar 2020 Disponivel em: http://www.ihu.unisinos.br/159-noticias/entrevistas/597307-sem-democracia-semciencia-sem-educacao-sem-renda-sem-politicas-sociais-e-sem-direitos-seguiremos-muito-doentesentrevista-especial-com-deisy-ventura. Acesso em 02 ago. 2020.

${ }_{69}$ BUTLER, Judith. Sin miedo: Formas de resistencia a la violencia de hoy. Penguin Random House Grupo Editorial España. Edição do Kindle, 2020. p. 418. 
podendo ser um ponto de partida a fim de compreender e de superar os desafios e os limites da realidade brasileira em tempos de pandemia.

\section{REFERÊNCIAS}

BUTLER, Judith. Vida precaria: el poder del duelo y la violencia. Buenos Aires, Argentina: Paidós, 2009.

BUTLER, Judith. Cuerpos que importan: sobre los limites materiales y discursivos del "sexo". Buenos Aires, Argentina: Paidós, 2012.

BUTLER, Judith. Qu'est-ce qu'une vie bonne? Paris, França: Éditions Payot \& Rivages, 2014.

BUTLER, Judith. Cuerpos aliados y lucha política. Buenos Aires, Argentina: Paidós, 2017.

BUTLER, Judith. Sin miedo: Formas de resistencia a la violencia de hoy. Penguin Random House Grupo Editorial España. Edição do Kindle, 2020.

CASTRO, Edgardo. Vocabulário de Foucault. Um percurso pelos seus temas, conceitos e autores. Belo Horizonte: Autêntica Editora, 2016.

DIAS, Renato Duro; BRUM, Amanda Netto. (Re)significando o discurso dos direitos humanos: um diálogo a partir da educação em e para os direitos humanos. Revista Quaestio iuris. vol. 10, n. 04. Rio de Janeiro, 2017. pp. 2396-2412.

ESTADÃO CONTEÚDO. No Twitter, Bolsonaro compartilha vídeo criticando isolamento social. Exame, 11 abr. 2020. Disponível em: https://exame.com/brasil/no-twitter-bolsonarocompartilha-video-criticando-isolamento-social/. Acesso em: 05 ago. 2020.

FOUCAULT, Michel. Em defesa da sociedade: curso do Collège de France (1975-1976). São Paulo: Martins Fontes, 2005.

FOUCAULT, Michel. As palavras e as coisas. São Paulo: Martins Fontes, 2007.

FOUCAULT, Michel. Nascimento da Biopolítica: curso dado no Collège de France (1978-1979). São Paulo: Martins Fontes, 2008.

FOUCAULT, Michel. Microfísica do poder. Rio de Janeiro: Paz e Terra, 2010.

FOUCAULT, Michel. Vigiar e punir. Petrópolis, RJ: Vozes, 2014.

FOUCAULT, Michel. O sujeito e o poder. Ditos e Escritos - IX. Rio de Janeiro: Forense Universitária, 2014.

FREITAS, André Ricardo Ribas; NAPIMOGA, Marcelo; DONALISIO, Maria Rita. A análise da gravidade da pandeia de COVID-19. Disponível em: 
http: / / www.scielo.br/scielo.php?script=sci_arttext\&pid=S2237-96222020000200900 . Acesso em: 02 ago. 2020.

HAN, Byung-Chul. Sociedade do cansaço. Petrópolis, RJ: Vozes, 2015.

HAN, Byung-Chul. Psicopolítica - o neoliberalismo e as novas técnicas de poder. Belo Horizonte: Editora Âyiné, 2018.

INSTITUTO BRASILEIRO DE GEOGRAFIA E ESTATÍ́STICA. PNAD Contínua 2019: rendimento do 1\% que ganha mais equivale a 33,7 vezes o da metade da população que ganha menos. Editoria: Estatísticas Sociais, 06 maio 2020. Disponível em:

https://agenciadenoticias.ibge.gov.br/agencia-sala-de-imprensa/2013-agencia-denoticias/releases/27594-pnad-continua-2019-rendimento-do-1-que-ganha-mais-equivale-a-33-7vezes-o-da-metade-da-populacao-que-ganha-menos. Acesso em: 02 ago. 2020.

KADNER, Marién. Judith Butler: “Matar é o ápice da desigualdade social”. Filósofa norteamericana, alvo de protestos no Brasil no ano passado por sua teoria sobre gênero, prepara uma nova obra sobre a ética da não violência. El País. Caderno de Cultura. 27 nov. 2018. Disponível em: https: //brasil.elpais.com/brasil/2018/11/27/cultura/1543350943_401404.html Acesso em: 02 ago. 2020.

MINISTÉRIO DA SAÚDE. Painel Coronavírus. Disponível em: https://covid.saude.gov.br/. Acesso em: 05 ago. 2020.

MUNIZ, Bianca; FONSECA, Bruno; PINA, Rute. Em duas semanas, número de negros mortos por coronavírus é cinco vezes maior no Brasil. Publica, 06 maio 2020. Disponível em: https: / / apublica.org/2020/05/em-duas-semanas-numero-de-negros-mortos-por-coronavirus-ecinco-vezes-maior-no-brasil/. Acesso em: 02 ago. 2020.

NOIS. Núcleo de Operações e Inteligência em Saúde. Inteligência computacional aplicada à predição da evolução da COVID-19 e ao dimensionamento de recursos hospitalares. Disponível em: https://drive.google.com/file/d/1_whlqZnGgvqHuWCG4-JyiL2X9WXpZAe3/view Acesso em: 02 ago. 2020.

OHARA, Victor. MPF processa governo por campanha de Bolsonaro pelo fim do isolamento. Carta Capital Saúde. 06 abr. 2020. Disponível em: https://www.cartacapital.com.br/saude/mpfprocessa-governo-por-campanha-de-bolsonaro-pelo-fim-do-isolamento/ Acesso em: 02 ago. 2020.

ORGANIZACIÓN MUNDIAL DE LA SALUD. Cronología de la respuesta de la OMS a la COVID-19. 30 jun. 2020. Disponível em: https://www.who.int/es/news-room/detail/29-06-2020covidtimeline. Acesso em: 02 ago. 2020.

ROSE, Nikolas. Governing the soul: the shaping of the private self. 2. Ed. Free Association Books, London/New York, 1999.

TESINI, Brenda T. Coronavírus e síndromes respiratórias agudas (COVID-19, MERS e SARS). Disponível em: https://www.msdmanuals.com/pt-pt/profissional/doen\%C3\%A7asinfecciosas/v\%C3\%ADrus-respirat\%C3\%B3rios/coronav\%C3\%ADrus-e-s\%C3\%ADndromesrespirat\%C3\%B3rias-agudas-covid-19,-mers-e-sars\#v47572272_pt Acesso em: 02 ago. 2020. 
VENTURA, Deisy. Entrevista especial com Deisy Ventura. [Entrevista cedida a] João 23 mar 2020 Disponível em: http://www.ihu.unisinos.br/159-noticias/entrevistas/597307-semdemocracia-sem-ciencia-sem-educacao-sem-renda-sem-politicas-sociais-e-sem-direitosseguiremos-muito-doentes-entrevista-especial-com-deisy-ventura Acesso em: 02 ago. 2020.

WERMUTH, Maiquel Ângelo Dezordi Wermuth; MORAIS, José Luis Bolzan de Morais. Da exceção agambeniana à constituição planetária de Ferrajoli: desafios impostos pela pandemia do novo coronavírus às categorias jurídico-políticas tradicionais. Revista Eletrônica do Curso de Direito da UFSM, v. 15, p. 1-29, 2020. Disponível em: https://periodicos.ufsm.br/revistadireito/article/view/43057. Acesso em: 02 ago. 2020.

WORLD HEALTH ORGANIZATION. Coronavirus disease (COVID-19) pandemic. Disponível em: https://www.who.int/emergencies/diseases/novel-coronavirus-2019 . Acesso em: 02 ago. 2020.

WORLD HEALTH ORGANIZATION. Coronavirus disease (COVID-19). Situation Report - 194. Disponível em: https: //www.who.int/docs/default-source/coronaviruse/situationreports/20200801-covid-19-sitrep-194.pdf?sfvrsn=401287f3_2. Acesso em: 02 ago. 2020.

WORLD HEALTH ORGANIZATION. Report of the WHO-China Joint Mission on Coronavirus Disease 2019 (COVID-19). Disponível em: https: / /www.who.int/docs/defaultsource/coronaviruse/who-china-joint-mission-on-covid-19-final-report.pdf. Acesso em: 10 abr. 2020.

\section{COMO FAZER REFERÊNCIA AO ARTIGO (ABNT):}

DIAS, Renato Duro. Governamentalidade, biopolítica e vida precária: a pandemia de Covid-19 no Brasil. Revista Eletrônica do Curso de Direito da UFSM, Santa Maria, RS, v. 15, n. 2, e43634, xxx./xx. 2020. ISSN 1981-3694. DOI: http://dx.doi.org/10.5902/1981369443634. Disponível em: https://periodicos.ufsm.br/revistadireito/article/view/43634. Acesso em: dia mês. ano.

Direitos autorais 2020 Revista Eletrônica do Curso de Direito da UFSM

Editores responsáveis: Rafael Santos de Oliveira e Angela Araujo da Silveira Espindola

Esta obra está licenciada com uma Licença Creative Commons Atribuição-NãoComercial-SemDerivações 4.0 Internacional.

\section{SOBRE O AUTOR}

\section{RENATO DURO DIAS}

Pró-Reitor de Graduação da Universidade Federal do Rio Grande (FURG), estando vinculado a esta universidade como Professor da Faculdade de Direito, da Especialização em Educação em Direitos Humanos e do Programa de Pós-Graduação em Direito - Mestrado em Direito e Justiça Social. É Doutor em Educação com período de doutoramento sanduíche na Universidade de Lisboa, Portugal. 